\title{
Childhood Trauma as a Risk Factor of Adult Fear of Birth and the Preference of a Caesarean Section
}

\author{
Höpfner $C^{1}$, Schwartz $C^{2}$, Frommer $\mathrm{J}^{1}$, J unne $F^{1,4}$, \\ Walter $\mathbf{M}^{3}$ and Vogel $\mathbf{M}^{1 *}$ \\ ${ }^{1}$ Universitätsklinik für Psychosomatische Medizin und \\ Psychotherapie der Otto-von-Guericke-Universität \\ Magdeburg, Magdeburg, Germany \\ ${ }^{2}$ Psychiatrische Universitätsklinik, Ludwig-Maximilians \\ Universität, München, Germany \\ ${ }^{3}$ Universitätsklinik für Psychiatrie und Psychotherapie \\ der Universität J ena, J ena, Germany \\ ${ }^{4}$ University Hospital Tübingen, Department of \\ Psychosomatic Medicine and Psychotherapy, Tübingen, \\ Germany \\ *Correspondling author: Matthias Vogel, \\ Universitätsklinik für Psychosomatische Medizin \\ und Psychotherapie, Leipziger Straße 44, D-39120 \\ Magdeburg, Germany
}

Received: March 16, 2021; Accepted: May 07, 2021; Published: May 14, 2021

\begin{abstract}
Background: Tokophobia (TP) is linked to negative affect, posttraumatic distress and the request for Caesarean Section. Prior trauma and some corresponding personality features, including typical of borderline personality, contribute to TP. With the conflictual object of this fear being a relational one, TP is amenable to psychodynamic heuristics. We investigate Childhood Trauma $(\mathrm{CHT})$, emotional distress, dissociation and borderline personality organization (BPO) along with TP and the request for Caesarean Section in 153 pregnant women, based on the assumption that CS and TP represent the two sides of the same coin, and that their relationship would be rooted in correlates of trauma such as dissociation or BPO.
\end{abstract}

Method: We used the WIJMA questionnaire, the dissociative experience scale, the childhood trauma screener, the IPO-16, and the BSI-18, as well as Kendall's tau, linear regression and a mediation analysis.

Result: The wish for CS was associated with TP and occurred in $6.3 \%$ of the sample. Correlations showed between TP and BPO, emotional distress and $\mathrm{CHT}$. Linear regression revealed the prediction of TP by $\mathrm{CHT}$, and the effect of $\mathrm{CHT}$ on the wish for CS was fully mediated by TP. Ambivalence regarding the preferred mode of birth coincided with the greatest emotional distress including TP. Dissociation did not contribute to TP.

Discussion: $\mathrm{CHT}$ may be a cornerstone of the psychodynamics leading to the preference of CS over natural birth. TP mediates the respective effects on the wish for CS and may reproduce the ambivalence of childhood experiences of interpersonal adversity. BPO

Keywords: Tocophobia; Posttraumatic; Childhood trauma; Dissociation

\section{Introduction}

Hofberg and Brockington [1] were the first to describe the phenomenon of exaggerated fear of childbirth or Tokophobia (TP). While an apprehension or fear of birth is normal [2], TP is defined as a spectrum ranging from minor to extreme fear in relation to labor and birth. The expression of TP is subject to a Gaussian distribution [2], with $5-10 \%$ of pregnant women experiencing severe anxiety and fear of birth. In turn, the postpartum incidence of posttraumatic distress amounts to $2.8-5.6 \%$ [3]. Not unlike other specific fears [4], TP is apparently nested with negative affectivity, i.e. anxiety and depression, and has a reported prevalence of $>20 \%$ in Western countries according to the cited review [5]. In addition, TP shows linkage with prior trauma or abuse [6]. Such a history of trauma is also consistent with the finding of a high incidence of PTSD in the aftermath of childbirth [7], since prior trauma often creates the susceptibility for PTSD [8]. Psychological trauma, e.g. abuse or neglect, is intervowen with psychic as well as psychosomatic lability as it often leads to not only dimensional, but also categorical constellations of various symptoms including of emotional, relational and behavioural kinds. For example, trauma is linked to negative affectivity, somatization, and to certain personality constellations including borderline personality, which is characterized by frequent mood changes and instable interpersonal bonding [4]. That aside, cognitive errors are of importance for both, negative affectivity and content-related (i.e. specific) fears [9] , such as TP. Content-related anxieties and negative affect share the additional commonality of being linked to prior trauma and to cognitive errors, at the same time $[6,10-12]$. Catastrophization was found to be associated with the anticipation of TP and the preferred mode of birth [13]. In addition to cognitive aspects, TP presents as an anticipation, which also involves another object, the unborn, and is thus amenable to psychodynamic interpretation, in principle. The latter, as a rule, acknowledges the individual's biographic predispositions in terms of interpersonal experiences. Object-related fear is a facet of personality structure and attachment insecurity, both of which are related to childhood adversities [14]. The psychodynamic view of BPD acknowledges the importance of adverse childhood experiences by stressing the importance of psychodynamic defenses for diagnosing and understanding borderline states [15]. Such defenses serve the prevention of trauma-related perceptions and memories but may, at the same time, be inductors of phobic anxiety [4]. TP itself may therefore be a correlate of childhood trauma and attachment difficulties which the experience of interpersonal trauma has encoded in the personality. Accordingly, TP co-varies with personality traits [2], including the ones typical of BPD [16], such as detachment,
Austin J Psychiatry Behav Sci - Volume 7 Issue 1 - 2021 ISSN : 2381-9006 | www.austinpublishinggroup.com Vogel et al. (C) All rights are reserved
Citation: Höpfner C, Schwartz C, Frommer J, Junne F, Walter M and Vogel M. Childhood Trauma as a Risk Factor of Adult Fear of Birth and the Preference of a Caesarean Section. Austin J Psychiatry Behav Sci. 2021; 7(1): 1078. 
impulsivity guilt, and others. The latter correspond to emotional instability and other features of BPD, which is also characterized by specific psychodynamics termed Borderline Personality Organization (BPO) [15]. Amongst others, BPO implies the predominant use of specific psychological defenses such as introjection.

The distress associated with an individual pregnancy is likely intensified by such an emotionally destabilising predisposition. Along these lines, dissociation is part of the spectrum of posttraumatic distress and comprises e.g. derealisation and depersonalization [4]. Indeed, a recent review has shown a very substantial burden of psychic as well as psychosomatic distress among pregnant women [17], and strikingly, somatoform and dissociative disorders turned ou to be the leading comorbidities (25\%), followed by anxiety (17\%), acute stress reaction (12\%) and depression (9\%). This pattern of comorbidity highlights the relevance of a history of trauma, since these comorbidities are linked to trauma, especially as regards somatoform and dissociative disorders $[18,19]$. Hence, trauma and posttraumatic distress seem to accentuate $\mathrm{TP}$, and to possibly increase the risk of a traumatic or re-traumatizing birth experience. As a consequence of marked TP, pregnant women seem to request CS in increasing numbers. In addition to psychosomatic and psychodynamic pathways to tokophobia and the request for CS, the respective motivation also corresponds to childbearing womens' sociodemographic characteristics which are changing over time: With primiparae getting older, also the numbers of individual birth experiences decline. Against this background, Mylona and Friese [20] have reported the incidence of CS to have more than doubled from $15.3 \%$ in 1991 to 31.7 in 2012.

The present study investigates levels of TP and their nestedness with negative affect, including dissociative symptoms. It also investigates BPO along with childhood trauma in order to find predictors of TP, as well as of the inclination to request a CS, although CS may not be the most appropriate answer to a psychodynamic causation of the fear of birth. Therefore, the present study tests the following hypotheses:

- TP is linked to childhood trauma as well as to its correlates, dissociation and BPO.

- $\quad$ TP is nested with psychopathologic distress.

- $\quad$ The wish for CS results from the experience of childhood trauma based on a posttraumatic pathway.

\section{Methods}

Participants were recruited at the "Helios" - Pasing hospital in Munich, Germany, based on their written informed consent in compliance with the human subjects review committee of the Medical Faculty of the Otto-von-Guericke-University, Magdeburg (approval nr: 139/17).

In order to reach a power of 0.95 , the study required 134 participants (analyzed by means of $\mathrm{g}^{\star}$ power) [21]. However, 153 women participated in the study based on prior informed consent. Mean gestational time was 33.96 (4.3) weeks. The sample is described in Table 1.

The participants were asked for their preferred mode of birth yielding the three categories: 1) vaginal/natural birth;2) caesarean section and 3) not sure/ ambivalent.

\section{Questionnaire measures}

The Wjima delivery expectancy (version A) questionnaire comprises 33 Items in a 5 point Likert-format with scores ranging between 0 and 165 and measures the different dimensions of the fear of childbirth: "fear", "negative appraisal", "loneliness", "lack of selfefficacy", "lack of positive anticipation" and "concerns for the child" $[22,23]$. Validity as well as reliability of the W-DEQ are judged good, and Cronbach's a reported to be 0.93. Calderani et al. [24] found scores $>85$ to be clinically relevant, and scores $>100$ to be pathologic.

The Brief Symptom Inventory (BSI-18), a short version of the symptom check list 90, assesses symptoms of depression, anxiety and somatization in three subscales. Internal consistency for the subscales ranges between 0.79 and 0.91 , discriminant and convergent validity are deemed good, and the scale is useful as a screening for psychological distress in physically ill populations [25,26]. Its total score is a measure of the global symptom load (or emotional labilization) and termed Global Severity Index (GSI).

The Fragebogen zu Dissoziativen Symptomen (FDS) represents the German version of the dissociative experiences scale, of which we used the short form (FDS-20). The FDS-20 is composed of the most sensitive items of the longer version on condition they reach a Cronbachs $\alpha$ of at least 0.9 [27]. The total scale has a good internal consistency ( $\alpha=0.93$ ). The FDS-20 is mainly validated at the total scale level but contains items that refer to the dissociative dimensions of amnesia, derealiziation, absorption, and conversion. The purpose of the FDS-20 is the screening for dissociative symptoms in clinical populations. Items are rated in terms of frequency on a scale ranging from never present $(0 \%)$ to always present $(100 \%)$.

The borderline personality inventory (IPO-16) is based on Kernberg's model of personality organization and reflects the criteria of borderline personality organization, i.e. reality testing, predominance of primitive defenses and diffusion of the identity [14]. The IPO-16 consists of three subscales assessing reality testing, predominance of primitive defenses and diffusion of the identity, but also results in a total score (IPO-total). In addition, a cut-of score serves the categorical diagnosis of BPD, and Cronbach's a of the German version of the IPO 16 is 0.86 and the scale shows a good testretest reliability [28].

The Childhood Trauma Screener (CTS) is a five-item-self-report instrument assessing childhood emotional, physical and sexual abuse, as well as childhood emotional and physical neglect. The CTS is derived from the longer childhood trauma questionnaire for the use as a screening for childhood trauma. Cronbach's $\alpha$ of the CTS is 0.75 , and it is judged to be reliable and valid for its purpose [29]. In addition, a cut-off score for every category allows for the categorical interpretation of the CTS. Participants were asked for their preferred birth mode and categorized accordingly as inclined to natural birth, CS or undetermined based on their answers.

\section{Statistical method}

We used $\chi^{2}$-testing to compare categories and correlation (Kendall's tau) to explore the relationships between the continuous 
variable W-DEQ (TP) with the above mentioned psychometric scales. Reported results are understood as two-tailed, and p was set at 0.05 . Linear regression was used for the prediction of TP. All regressions were controlled for age, and no stepwise procedure was applied. Mediation analyses were performed using the PROCESS macro by Hayes [30], which uses ordinary least squares regression, yielding unstandardized path coefficients for total, direct, and indirect effects. Bootstrapping with 5000 samples together with heteroscedasticity consistent standard errors [31] were employed to compute the confidence intervals and inferential statistics. Effects were deemed significant when the confidence interval did not include zero.

\section{Results}

Participants were 32.44 (4.83) years old. Of them, 65 (42.48\%) fell into the category of primiparae, and $31(20.26 \%)$ disclosed their willingness to opt for CS $\left(\chi^{2}=1.76, p=0.2\right)$. Eight (5.23\%) scored above the cut-off of the IPO-16. The resulting category of BPD was associated with the inclination for CS $\left(\chi^{2}=0.02\right)$, but not with TP as a category (based on the cut-off of 85$)\left(\chi^{2}=2.17, p=0.3\right)$. Of the eight participants with BPD, $1(12.5 \%)$ also fell into the category of TP, whereas 7 (87.5\%) did not. With the cut-off of the WDEQ set at 100, as suggested to capture pathologic TP [24], the number of participants with pathologic TP and categorial BPD, respectively, is $6(77.8 \%) v s .2$ (22.2\%) with $\mathrm{BPO}$ yet without $\mathrm{TP}\left(\chi^{2}=4.92, \mathrm{p}=0.08\right)$.

The expression of TP was low in 7 (4.9\%), moderate in 67 (47.2\%), high in $48(33.8 \%)$ and very high in 11 (7.8\%) of the participants.

The W-DEQ total score and the number of gestational weeks sowed no correlation $(\mathrm{r}=0.05)$. However, correlations showed between the W-DEQ total score and the IPO-16, as well as childhood trauma screener total scores (the correlational matrix is presented in Table 3) and the global severity index.

Despite the manifold correlations between TP and symptoms reported above, the categorical presence of (any) childhood trauma emerged as the sole predictor of the WDEQ total score. As shown by means of a mediation analyses (Figure 1), the present results reflect the mediation of the effects of childhood trauma on the wish for CS by tokophobia.

A simple mediation was performed to analyze whether childhood trauma scores predict the wish for caesarean section and whether

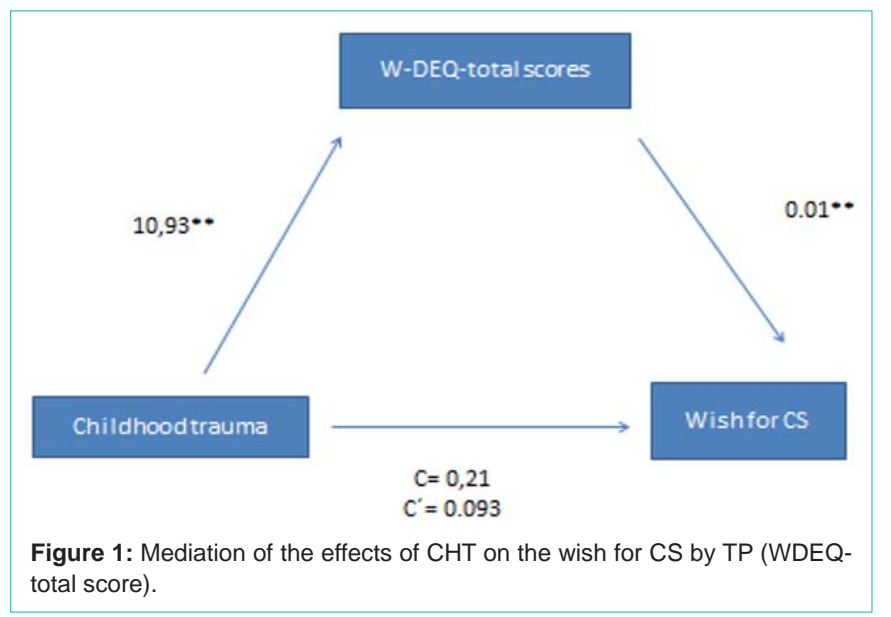

Table 1: Sociodemographic description of the sample.

\begin{tabular}{|c|c|}
\hline Age (yrs.) $M(S D)$, Range & 32.44 (4.83), $19-43$ \\
\hline Gestational week $M(S D)$, Range & 33.96 (4.33), $18-41$ \\
\hline \multicolumn{2}{|l|}{ Sociodemographics $n$ (\%) } \\
\hline Single & $35(22.9)$ \\
\hline Married & $92(60.1)$ \\
\hline Separated & $1(0.7)$ \\
\hline Divorced & $3(2.0)$ \\
\hline No information & $22(14.4)$ \\
\hline \multicolumn{2}{|l|}{ Professional degree $n(\%)$} \\
\hline Still in apprenticeship & $2(1.3)$ \\
\hline Apprenticeship complete & $78(50.9)$ \\
\hline University & $39(25.5)$ \\
\hline No degree & $7(4.6)$ \\
\hline Other & $4(2.6)$ \\
\hline No information & $23(15.0)$ \\
\hline \multicolumn{2}{|l|}{ Job situation } \\
\hline Working fulltime & $37(24.2)$ \\
\hline Employment ban & $7(4.6)$ \\
\hline Maternity protection & $74(48.4)$ \\
\hline House wife & $3(2.0)$ \\
\hline Apprentice ship & $1(0.7)$ \\
\hline jobless & $1(0.7)$ \\
\hline No information & $30(19.6)$ \\
\hline \multicolumn{2}{|l|}{ Wishing caesarean section $\mathrm{n}(\%)$} \\
\hline Yes & $31(20.3)$ \\
\hline No & $100(65.4)$ \\
\hline Undetermined & $22(14.3)$ \\
\hline
\end{tabular}

Table 2: Mean/SD of the variables of interest (total scores of the FDS/DES, IPO$16, \mathrm{BSI}-18$ and ithe WDEQ) in the groups wishing either CS or natural birth, or being ambivalent, respectively.

\begin{tabular}{|c|c|c|c|c|c|}
\hline \multicolumn{2}{|c|}{ Group (n) } & FDS 20 & IPO-16t & GSI & WDEQ \\
\hline \multirow{2}{*}{ Ambivalent (11) } & MW & 10,05 & 1,85 & 0,93 & 2,44 \\
\cline { 2 - 6 } & SD & 14,14 & 0,49 & 0,49 & 0.67 \\
\hline \multirow{2}{*}{ CS (31) } & MW & 7,95 & 1,67 & 0,79 & 2.2 \\
\cline { 2 - 6 } & SD & 8,02 & 0,44 & 0,27 & 0,63 \\
\hline \multirow{2}{*}{ Nat. Birth (100) } & MW & 7,05 & 1,78 & 0,79 & 2,02 \\
\cline { 2 - 6 } & SD & 6,81 & 0,39 & 0,26 & 0,55 \\
\hline
\end{tabular}

the direct path would be mediated by the WDEQ-total-scores. No significant effect of $\mathrm{CHT}$ on the wish for CS was observed, $\mathrm{B}=0.21$, $\mathrm{p}=0.02$. After entering the mediator into the model, CHT predicted the mediator significantly, $\mathrm{B}=0.27, \mathrm{p} .001$, which in turn predicted the wish for CS significantly, $\mathrm{B}=0.25, \mathrm{p}=0.01$. We found that the relationship between $\mathrm{CHT}$ and the request for CS is fully mediated by the WDEQ, indirect effect $a b=0.12,95 \%$ CI $[0.03,0.27]$.

\section{Discussion}

The present study investigated the role of borderline personality 
Table 3: Correlational matrix between the variables of interest.

\begin{tabular}{|l|c|c|c|c|c|c|}
\hline & $\mathbf{1}$ & $\mathbf{2}$ & $\mathbf{3}$ & $\mathbf{4}$ & $\mathbf{5}$ & $\mathbf{6}$ \\
\hline WDEQ total & 1 & $0.14^{\star}$ & 0.085 & $0.152^{\star}$ & $0.163^{\star *}$ & -0.085 \\
\hline IPO-total & $0.14^{\star}$ & 1 & $0.36^{\star *}$ & $0.174^{\star *}$ & $0.621^{\star *}$ & 0.008 \\
\hline FDS-20- & 0.085 & $0.36^{\star \star}$ & 1 & $0.135^{\star}$ & $0.341^{\star \star}$ & $-0.246^{\star \star}$ \\
\hline CTS-total & $0.152^{\star}$ & $0.174^{\star *}$ & $0.135^{\star}$ & 1 & $0.206^{\star *}$ & 0.006 \\
\hline GSI & $0.163^{\star \star}$ & $0.621^{\star *}$ & $0.341^{\star *}$ & $0.206^{\star *}$ & 1 & -0.017 \\
\hline Age & -0.09 & 0.01 & $-0.25^{\star \star}$ & 0.01 & -0.02 & 1 \\
\hline
\end{tabular}

WDEQ: Tokophobia; IPO: Inventory for the assessment of BPO; CTS: Childhood Trauma Screener; GSI: Global Severity Index.

Table 4: Linear Regression.

\begin{tabular}{|l|c|c|c|c|c|c|c|}
\hline & $\mathbf{B}$ & $\mathbf{S E}$ & $\boldsymbol{B}$ & $\mathbf{t}$ & $\mathbf{p}$ & Ci Lower & Ci Upper \\
\hline FDS 20 & 0.004 & 0.007 & 0.061 & 0.591 & 0.556 & -0.01 & 0.018 \\
\hline GSI & 0.396 & 0.256 & 0.205 & 1.545 & 0.125 & -0.111 & 0.904 \\
\hline IPO-ID- & 0.059 & 0.116 & 0.061 & 0.509 & 0.612 & -0.17 & 0.288 \\
\hline IPO-PD- & 0.001 & 0.11 & -0.001 & -0.005 & 0.996 & -0.218 & 0.217 \\
\hline IPO-RT- & 0.094 & 0.145 & -0.072 & -0.648 & 0.518 & -0.381 & 0.193 \\
\hline CHT & 0.256 & 0.103 & 0.21 & 2.487 & 0.014 & 0.052 & 0.459 \\
\hline
\end{tabular}

Dependent Variable: WDEQ Total Score/Tokophobia; FDS 20: dissociation; GSI: Global Severity Index; IPO: inventory for the assessment of BPO, ID: Identity Diffusion, PD: Primitive Defenses; RT: Reality Testing; CHT: Presence of $<1$ Childhood Trauma acc. to the Childhood Trauma Screener.

organization, dissociation and childhood trauma for TP and the request for CS based on findings pointing to an involvement of trauma as well as of posttraumatic conditions in the experience of TP [32]. We found correlations between TP on the one hand, and borderline personality organization, childhood trauma scores and the symptom load as represented by the GSI, on the other. The present findings are in-line with research reporting the marked expression of emotional distress among pregnant women, and it corroborates prior findings with regard to dissociation [16]. Moreover, the connection between TP, the request for CS and childhood-trauma is a corroboration of prior findings [11,33] reporting personality traits and posttraumatic distress to be associated with TP. Pregnancy and the prospect of giving birth confront the pregnant woman with a stressful kind of anticipation including the reflection of risks, which more often leads to emotional distress in the presence of psychiatric comorbidity [2,16], than it does in its absence. Sydsjö and co-authors [17] have identified an increased burden of severe psychiatric illness among women who opt for CS. In addition to this, women with TP are known to be twice as likely to have been in psychotherapeutic treatment, compared to women without TP [17]. The present study is consistent with that research because it demonstrates the nestedness of TP with both, negative affective symptoms and BPO, although the presence of a childhood traumatization on the part of the mother emerged as the sole predictor of TP. Strikingly, however, we cannot establish a pathway which would include dissociation or BPO, as hypothesized. TP might therefore represent a specific modality of a childhood-trauma-related symptomatology in pregnant women. Given that the ambivalent group is most distressed as far as all measures were concerned, indicating the ambivalence towards the modality of birth to be the most distressful outcome, the posttraumatic nature of TP may manifest as a dissociation of attachment rather than a fragmentation of the usually integrated functions relevant to dissociation. Generally, pregnant women suffer from dissociation more often than the general population, yet more rarely than late adolescents [34], although the denial of pregnancy is reported to be embedded in dissociative phenomena [35], and childbirth sometimes leads to dissociative experiences [36,37].

Notably, the present study shows ambivalence as to the mode of delivery to be the most burdensome motivational state regarding pregnancy, and ambivalence in this context could be reflective of the paradox relational motivations, and of the psychodynamics so typical of borderline states [38]. Thus, the object of TP may not be the event of delivery, but rather the interpersonal proximity and obligation inherent to the anticipated mother-child relationship.

The rate of $\mathrm{BPD}$, as assessed using the IPO-16, in the present study was equal to its reported prevalence in non-psychiatric samples [39], suggesting the sample to be representative of a non-psychiatric population. This correlation between $\mathrm{BPO}$ and $\mathrm{TP}$, and its connection to childhood trauma may indicate a functionally regressed state reflecting the difficulty adapting to the physical changes as well as to the relational object "under development". A temporary, functional deterioration of ego functions has been described in the context of physical illness [40] and outlined as a condition of reduced self-confidence, along with an increased vulnerability for feelings of loss, being offended or at the mercy of fate [38]. Such an inner constellation of helplessness fosters relational ambivalence in borderline personality states [38]. Likewise, stress can activate and increase the use of defense mechanisms, e.g. in connection with physical illness or medical treatment [41]. Disavowal defenses, such as denial, are sometimes also employed during pregnancy [42]. On the contrary, dissociative defenses are not extraordinarily frequent in pregnant women [43], although higher on average than in the general population [34], especially in women who also report childhood abuse [44]. However, ambivalence and stress can activate and increase the use of such fundamental defenses, e.g. in connection with medical treatment [41]. This notwithstanding, one may consider the role of dehydroepiandrosterone in this context, which is a precursor of both, female and male sex hormones [45], apparently an inhibitor of dissociative responses [45], and increased in pregnancy [46]. Thus one may speculate, whether the present results as to dissociative phenomena are possibly an expression of their suppression by hormonal influences during pregnancy. Hence, if one considers the epidemic of childhood abuse and neglect [48], the individual burden of TP and the corresponding request for CS may reflect an effect of CHT without a dissociative mediation. The present results suggest the dynamics of ambivalence to be rooted in childhood trauma and to be cognitively and emotionally involved in the request for CS, with exaggerated TP being the clinical and cognitive condensation of the own ambivalent experience with abusive caregivers. Pregnancy could therefore be the occasion on which the effect of childhood trauma is being brought to bear in the form of TP. Thus, the association between TP and childhood trauma is apparently reflective of the fundamental relational disturbance, which can result from early adverse interpersonal experience. This notion highlights the importance of the mother's own relational history for the process of anticipating and finally building a relationship with the unborn child, and is in-line with recent studies reporting a subgroup of pregnant women with pronounced traumatic distress during and 
after pregnancy [49]. As discussed above, this distress may manifest as the correlate of childhood abuse. Likewise, personality features such as emotional lability (or neuroticism) are linked to childhood trauma [50] and to the inclination for a caesarean section, as well [5]. Thus, the easily feasible screening for childhood trauma may be a reasonable diagnostic addition to contemporary proceedings in obstetrics.

The present study was cross-sectional in nature, did not include diagnostic interviews and is based on a sample restricted in size. This clearly warrants caution at the interpretation of the present results. The assessments took place between the 18th and 41st gestational week, creating possible internal variance. However, the number of gestational weeks and TP seemed statistically unrelated in the present data. This notwithstanding, the present study corroborates the clinical usefulness of the threshold of the WDEQ at 100 which we show to be more sensitive in the realm of the psychodynamic underpinnings of TP. Not least, the present preliminary findings underscore the importance of psychosomatic factors in obstetrics. In particular, it suggests a simple screening for $\mathrm{CHT}$ as a pre-emptive measure to identify patients at risk of maladaptation to pregnancy, who might, in addition, benefit from psychosocial support prior to childbirth.

\section{Conclusion}

TP may lead to non-indicated CS as a consequence of specific fear. The latter has a psychodynamic component and its trace can be followed psychometrically. According to the present study, CHT paves the way for adult TP and may therefore serve the pre-emptive identification of mothers at risk of a psychodynamically driven request for $\mathrm{CS}$.

\section{Acknowledgment}

We thank M.Sc. Elke Mattern (Martin Luther University HalleWittenberg, Institute of Health and Nursing Science, Halle (Saale), Germany) for providing her German translation of the W-DEQ.

\section{Ethical Approval}

All procedures performed in this study were in accordance with the ethical standards of the institutional and/or national research committee and with the 1964 Helsinki declaration and its later amendments or comparable ethical standards.

Informed consent was obtained from all individual participants included in the study.

\section{References}

1. Hofberg K, Brockington I. Tokophobia: an unreasoning dread of childbirth. A series of 26 cases. Br J Psychiatry. 2000; 176: 83-85.

2. Ryding EL, Wirfelt E, Wängborg IB, Sjögren B. Personality and fear of childbirth. Acta Obstetricia et Gynecologica Scandinavica.2007; 86:7; 814820 .

3. Olde E, van der Hart O, Kleber R, van Son M. Posttraumatic stress following childbirth: a review. Clin Psychol Rev. 2006; 26: 1-16.

4. Vogel M, Meyer F, Frommer J, Walter M, Lohmann $\mathrm{CH}$, Croner R. Unwillingly traumatizing: is there a psycho-traumatologic pathway from general surgery to postoperative maladaptation? Scandinavian Journal of Pain. 2020.

5. Rondung E, Thomtén J, Sundin Ö. Psychological perspectives on fear of childbirth. J Anxiety Disord. 2016; 44: 80-91.

6. Heimstad R, Dahloe R, Laache I, Skogvoll E, Schei B. Fear of childbirth and history of abuse: Implications for pregnancy and delivery. Acta Obstetricia Et Gynecologica Scandinavica. 2006; 85: 435-440.

7. Dikmen-Yildiz P, Ayers S, Phillips L. Longitudinal trajectories of posttraumatic stress disorder (PTSD) after birth and associated risk factors. J Affect Disord. 2018; 229: 377-385.

8. Dorrington S, Zavos H, Ball H, McGuffin P, Sumathipala A, Siribaddana S, et al. Family functioning, trauma exposure and PTSD: A cross sectional study. J Affect Disord. 2019; 245: 645-652.

9. Vancleef LM, Vlaeyen JW, Peters ML. Dimensional and componential structure of a hierarchical organization of pain-related anxiety constructs. Psychol Assess. 2009; 21: 340-351.

10. Laursen M, Johansen C, Hedegaard M. Fear of childbirth and risk for birth complications in nulliparous women in the Danish National Birth Cohort. BJOG. 2009; 116: 1350-1355.

11. Lukasse M, Vangen S, Øian P \& Schei B. Fear of childbirth, women's preference for cesarean section and childhood abuse: A longitudinal study. Acta Obstetricia Et Gynecologica Scandinavica. 2011; 90: 33-40.

12. Vogel M, Krippl M, Frenzel L, Riediger C, Frommer J, Lohmann C, et al. Dissociation and Pain-Catastrophizing: Absorptive Detachment as a HigherOrder Factor in Control of Pain-Related Fearful Anticipations Prior to Total Knee Arthroplasty (TKA). J Clin Med. 2019: 8: E697.

13. Van den Bussche E, Crombez G, Eccleston C, Sullivan MJL. Why women prefer epidural analgesia during childbirth: The role of beliefs about epidural analgesia and pain catastrophizing. European Journal of Pain. 2007; 11: 275 282.

14. Fuchshuber J, Hiebler-Ragger M, Kresse A, Kapfhammer HP, Unterrainer $\mathrm{HF}$. The Influence of Attachment Styles and Personality Organization on Emotional Functioning After Childhood Trauma. Front Psychiatry. 2019; 10: 643.

15. Lenzenweger MF, Clarkin JF, Kernberg OF \& Foelsch PA. The Inventory of Personality Organization: Psychometric properties, factorial composition, and criterion relations with affect aggressive dyscontrol, psychosis proneness, and self-domains in a nonclinical sample. Psychological Assessment. 2001; 13: 577-591.

16. Ekselius L, Hetta J, von Knorring L. Relationship between personality traits as determined by means of the Karolinska Scales of Personality (KSP) and personality disorders according to DSM-III-R. Personality and Individual Differences. 1994; 16: 589-595.

17. Sydsjö G, Möller L, Lilliecreutz C, Bladh M, Andolf E, Josefsson A. Psychiatric illness in women requesting caesarean section. BJOG. 2015; 122: 351-358.

18. Bremner JD. Cognitive processes in dissociation: comment on Giesbrecht et al. (2008). Psychol Bull. 2010; 136: 1-11.

19. Spitzer C, Barnow S, Wingenfeld K, Rose M, Löwe B, Grabe HJ. Complex post-traumatic stress disorder in patients with somatization disorder. Aust $\mathrm{N}$ Z J Psychiatry. 2009; 43: 80-86.

20. Mylonas I, Friese K. Indications for and Risks of Elective Cesarean Section. Dtsch Arztebl Int. 2015; 112: 489-495.

21. Faul F, Erdfelder E, Lang A-G \& Buchner A. G*Power 3: A flexible statistical power analysis program for the social, behavioral, and biomedical sciences. Behavior Research Methods. 2007; 39: 175-191.

22. Garthus-Niegel S, Størksen HT, Torgersen L, Von Soest T, Eberhard-Gran M. The Wijma Delivery Expectancy/Experience Questionnaire: a factor analytic study. J Psychosom Obstet Gynaecol. 2011; 32: 160-163.

23. Wijma K, Wijma B, Zar M. Psychometric aspects of the W-DEQ: a new questionnaire for the measurement of fear of childbirth. J Psychosom Obstet Gynaecol. 1998: 19: 84-97.

24. Calderani E, Giardinelli L, Scannerini S, Arcabasso S, Compagno E, Petraglia $F$, et al. Tocophobia in the DSM-5 era: Outcomes of a new cut-off analysis of the Wijma delivery expectancy/experience questionnaire based on clinical presentation. J Psychosom Res. 2019: 116: 37-43.

25. Franke GH, Jäger S, Morfeld M, Salewski Ch, Reimer J, Rensing A, et 
al. Is the BSI-18 useful for screening for psychological distress in kidneytransplanted patients? Z Med Psychol. 2010; 19: 30-37.

26. Franke GH, Ankerhold A, Haase M, Jäger S, Tögel Ch, Ulrich $C$, et al. The usefulness of the Brief Symptom Inventory 18 (BSI-18) in psychotherapeutic patients. Psychother Psych Med. 2011; 61: 82-86.

27. Spitzer C, Stieglitz RD, Freyberger HJ. Fragebogen zu dissoziativen Symptomen (FDS). Ein Selbstbeurteilungsverfahren zur syndromalen Diagnostik dissoziativer Phänomene. Deutschsprachige Adaptation der Dissociative Experiences Scale (DES) von Bernstein-Carlson und F.W. Putnam (3., überarbeitete und erweiterte Auflage). Bern: Hans Huber. 2015.

28. Zimmermann J, Benecke C, Hörz S, Rentrop M, Peham D, Bock A, et al. Validierung einer deutschsprachigen 16-item-Version des Inventar de Persönlichkeitsorganisation (IPO-16). Diagnostica. 2013; 59: 3-16.

29. Grabe HJ, Schulz A, Schmidt CO, Appel K, Driessen M, Wingenfeld K, et al. A brief instrument for the assessment of childhood abuse and neglect: the Childhood Trauma Screener (CTS). Psychiatr Prax. 2012; 39: 109-115.

30. Hayes AF. Introduction to Mediation, Moderation, and Conditional Process Analysis, Second Edition (Methodology in the Social Sciences) $\left(2^{\text {nd }}\right.$ ed.). NY Guilford Press. 2018

31. Davidson R \& MacKinnon JG. Estimation and Inference in Econometrics Oxford: University Press. 1993

32. Rouhe H, Salmela-Aro K, Gissler M, Halmesmaki E, Saisto T. Mental health problems common in women with fear of childbirth. BJOG. 2011; 118: 11041111.

33. Lukasse M, Vangen S, Øian P, Kumle M, Ryding EL, Schei B, Bidens Study Group. Childhood abuse and fear of childbirth--a population-based study. Birth. 2010; 37: 267-274

34. Carlson EB \& Putnam FW. An update on the Dissociative Experiences Scale. Dissociation: Progress in the Dissociative Disorders. 1993; 6: 16-27.

35. Spinelli MG. Denial of pregnancy: a psychodynamic paradigm. J Am Acad Psychoanal Dyn Psychiatry. 2010; 38: 117-131.

36. Zambaldi CF, Cantilino A, Farias JA, Moraes GP, Sougey EB. Dissociative experience during childbirth. J Psychosom Obstet Gynaecol. 2011; 32: 204 209.

37. Leeners B, Görres G, Block E, Hengartner MP. Birth experiences in adult women with a history of childhood sexual abuse. J Psychosom Res. 2016; 83: 27-32.

38. Corradi RB. Ambivalence: its development, mastery, and role in psychopathology. Bull Menninger Clin. 2013; 77: 41-69.
39. Leichsenring F, Leibing E, Kruse J, New AS, Leweke F. Borderline personality disorder. Lancet. 2011; 377: 74-84.

40. Fritzsche K. Psychotherapy of patients with life threatening illness. (Psychotherapie bei lebensbedrohlich Erkrankten). Psychotherapeut. 2005; 50: 281-289.

41. Cramer P. Defense mechanisms and physiological reactivity to stress. J Pers 2003; 71: 221-244.

42. Wessel J, Endrikat J, Buscher U. Frequency of denial of pregnancy: results and epidemiological significance of a 1-year prospective study in Berlin. Acta Obstet Gynecol Scand. 2002; 81: 1021-1027.

43. Berthelot N, Lemieux R, Garon-Bissonnette J, Muzik M. Prenatal Attachment, parental Confidence, and Mental Health in Expecting Parents: The Role of Childhood Trauma. J Midwifery Womens Health. 2020; 65: 85-95.

44. Leeners B, Richter-Appelt H, Imthurn B, Rath W. Influence of childhood sexual abuse on pregnancy, delivery, and the early postpartum period in adult women. Journal of Psychosomatic Research. 2006; 61: 139-151.

45. Morgan CA $3^{\text {rd }}$, Rasmusson A, Pietrzak RH, Coric V, Southwick SM. Relationships among plasma dehydroepiandrosterone and dehydroepiandrosterone sulfate, cortisol, symptoms of dissociation, and objective performance in humans exposed to underwater navigation stress. Biol Psychiatry. 2009; 66: 334-340.

46. Tagawa N, Hidaka Y, Takano T, Shimaoka Y, Kobayashi Y, Amino N. Serum concentrations of dehydroepiandrosterone and dehydroepiandrosterone sulfate and their relation to cytokine production during and after normal pregnancy. Clin Chim Acta. 2004; 340: 187-193.

47. Di Giuseppe M, Ciacchini R, Micheloni T, Bertolucci I, Marchi L, Conversano C. Defense mechanisms in cancer patients: a systematic review. J Psychosom Res. 2018; 115: 76-86.

48. Oral R, Ramirez M, Coohey C, et al. Adverse childhood experiences and trauma informed care: the future of health care. Pediatr Res. 2016; 79: 227 233.

49. Yildiz PD, Ayers S, Phillips L. The prevalence of posttraumatic stress disorde in pregnancy and after birth: A systematic review and meta-analysis. J Affect Disord. 2017; 208: 634-645.

50. Cattane N, Rossi R, Lanfredi M, Cattaneo A. Borderline personality disorde and childhood trauma: exploring the affected biological systems and mechanisms. BMC psychiatry. 2017; 17: 221

51. Johnston RG, Brown AE. Maternal trait personality and childbirth: The role of extraversion and neuroticism. Midwifery. 2013; 29: 1244-1250. 